\title{
E-CRIME System: A Knowledge Management Application in Public Administration ${ }^{\star}$
}

\author{
Réka Vas, Barna Kovács, and András Gábor \\ Budapest University of Economic Sciences and Public Administration, Department of \\ Information Systems \\ \{rvas, bkovacs, gabor\}@informatika.bke.hu
}

\begin{abstract}
Legal security, which is an important factor of life quality, was the major subject of our research. We have concluded that legal security could be achieved by the perfection of jurisdiction, of which the three major elements are time, precision and efficiency [4. The final goal of an appropriately working juridical system is to find equilibrium between time and precision and this way to reach maximum efficiency. This paper will discuss in details the problems of the Hungarian juridical system, particularly those, which can be solved or supported by IT tools. Our research project will be demonstrated, in which after the analysis of laws and legal studies the knowledge mapping of this domain has been realized. Based on this, an ontology has been made and an expert system has been developed. Our paper also describes how an advanced information system can improve the efficiency of the juridical processes.
\end{abstract}

\section{Introduction}

Legal systems have basically two types: the Anglo-Saxon (precedent or casebased) and the continental (Prussian or rule-based) model. The Hungarian juridical system is a rule-based one.

In Hungary the functional disturbances of courts are well-known: unacceptably long proceedings are frequent, the overwork of judges is high, there are many administrative errors and backlogs, and information is often not available. Besides, the low level of manpower and scant technological resources cause further problems. Official procedures are legally well regulated, the workflow on the other hand is fully manual, there is little possibility for avoiding human errors. The management of judgment making process is not resolved and the transparency of proceedings also should be improved. Keeping in line with the technological-organizational-social environment and EU-conformity require substantial reorganizations in the work of courts, which can only be reached with the help of advanced information systems.

The purpose of our R\&D project is to support the modernization and development of juridical system by developing and testing new knowledge manage-

\footnotetext{
* The research was founded by the R\&D Division of the Ministry of Education under the frame of ICT program \#00136/2001.
} 
ment tools and procedures. The fundamental objective of our research project is to develop a citizen-friendly and cost-effective solution.

\section{Situation Analysis}

\subsection{Problems Due to the Lack of IT Support}

In the next few paragraphs we summarize and analyze those problems of the Hungarian juridical system, for which we tried to find an appropriate solution. A feasibility study has been made, which showed in details the problems of the Hungarian juridical system.

A comprehensive workflow system can handle almost all of these problems. The goal of our R\&D project was to analyze the feasibility of an expert system, which can effectively support the judgment making process, and if it is possible then develop a prototype system. All other parts of the workflow system are developed by other organizations independently. However we try to summarize the whole range of problems to make clear the position of our expert system in the workflow system.

In Hungary the lead-time of the juridical proceedings is very long. When someone commits some criminal action, the official process of investigation, prosecution by the Public Prosecutor's Office, appointment of date of trial, conduction of trial, appointment and conduction of subsequent trials, judgment making, filling of appropriate documents and execution can even take several years. Every step of this process can be and should be improved in favour of efficiency and effectiveness.

In every step of the above described process the recording of data and documentation is fully manual. All documents of a case are held in a single dossier, which can be processed by only one person at the same time. This way parallel work is impossible, which causes the slow-down of the whole process. Take judges as an example, since our research focuses on judgment making. There is a huge amount of cases, all documentation of which should be handled by the judges, and the result of this is a massive overwork. The most crucial consequence of overwork is the existence of great backlogs in the Hungarian courthouses. Another effect of the paper-based workflow is the large amount of human and administrative errors. These documents contain many identical information, for example the number of case, the name of defendant, etc., which has to be copied from one document to another and this increases the possibility of typos and other errors.

The most relevant problem, which can be solved by our expert system is the following: due to the rigid legal regulation even small formal errors, like the mistyping of a name or a number can lead to the voidability of proceedings. If the judgment is appealed with reference to formal errors then the proceeding of the first or second instance become totally useless since the case can be renewed on a higher level.

As a summary we can state that formal errors, overwork of judges and manual workflow influence adversely the quality of judgments, which is a relevant 
benchmark of the work of courthouses. From the set of quality factors the consistence of judgments must be emphasized. Different judges differently interpret laws and regulations and this way it can occur that in very similar cases they may return very different verdicts.

Finally, there is a further effect of the manual workflow, which we also have to mention. Since documents are stored in dossiers and file departments and since the registry of these documents is modest, gathering and searching of information is difficult and often impossible, which cause information loss and serious cost overhead.

\subsection{Other Problems}

We also have to mention some other problems in connection with the Hungarian jurisdiction. First of all, there are organizational problems that also affect the current proceedings adversely.

The most exigent of them is the low level of manpower. In Hungary the juridical profession is prestigious, but not well paid. Besides, it takes a long time for someone to become a judge, because this profession is based on very conservative and rigid rules and conventions.

The scant technological resources also narrow the opportunities of judges. However there is a large development plan in this area, in which the courthouses can obtain a number of computers and local network infrastructure (communication infrastructure and server computers) can also be initiated with central and EU (Phare) support. A Phare program launched a development project, in which the overall development aims to significantly improve the ICT infrastructure, to develop a secure network and establish a secure PKI (Public Key Infrastructure) environment.

To achieve the goals of the above mentioned plan the judges have to be trained because their competence and IT skills are very low. As we previously mentioned the process to become a judge is long, and the current manpower of the courts is middle aged or senior. Due to the high workload and the lack of necessity of using IT tools they tailed off from the advance of IT. This lag also causes resistance to the installation and training of new IT systems. Of course there are also differences in regional sense, the eastern region of our country is less developed and even less motivated in the advance.

In the background there are also some management problems. The management - which also consists of judges - is not committed to IT, this way the priority of IT development is low. This seems to be changed by the current development plans, so a centrally controlled process has been started, but it will be difficult to handle the inflexibility of the regional management of courthouses.

The governance must also consider that the management of judgment making process is not resolved. It is a very complex proceeding, therefore not all judges can see through the whole process. This can also lead to further errors and omissions. For an outsider not working in the jurisdiction the proceedings are completely opaque. This also makes the control of the juridical work more difficult. 
The legal rules and proceedings are not optimized for computer aided workflow. The proceedings are however well regulated, but they are complex and contain elements based on conventions. The greatest difficulty we encountered is the diversity of the logic of judges. They have a way of thinking heading from global to details. This is in contrast to our system development concept, which in order to formalize procedures takes smaller elements first to handle the complexity of cases. Even the judge who followed every step of the pilot system development and helped us in this work could hardly accept this logic.

As a result of the thorough analysis of problems we argue that the judicial work can be supported on three levels:

- Knowledge-based system (rule-based or precedent (case) -based)

- Process automation system (workflow systems)

- Document warehouse, document mining

From this set of supporting elements our task was to investigate the most knowledge-intensive area, which is the aiding of judges' work and judgment making with a knowledge-based system. A pilot expert system has been developed, in which certain rules of the Hungarian Criminal Code have been formalized. The system gathers all input information and many modifiers (for example aggravation, extenuation, scope) necessary for the judgment and guides the judge in the forming of judgment. The purpose of this process is to determine a verdict, which stands on the top of rule base organized according the concepts of backward chaining. Backward chaining ensures that a verdict always matches the regulations of the law, if all the necessary information is available [6].

\section{System Development and Knowledge Structuring}

As we already mentioned, the main purpose of the research was to develop a prototype of an intelligent system, namely an expert system, to considerably improve the efficiency and effectiveness of knowledge intensive tasks of the Hungarian tribunals. The process of creating - intelligent - computer programs has four major elements, which must be well distinguished [7]. The following list not only describes all the major parts of our prototype system, but it also indicates the steps, the process of the development of our system.

\subsection{Domain Ontology}

The first element, which has to be distinguished, is the domain ontology. To give a definite description for the concept of ontology is a real challenge. In Artificial Intelligence (AI) ontologies have two different interpretations. First, ontology can mean a representation vocabulary. More precisely it means the conceptualization that the terms in the vocabulary are intended to capture. In this case ontology provides a set of terms, which describes the facts in a certain domain. 
In another sense the term of ontology refers to a body of knowledge describing a certain domain, usually a commonsense knowledge domain, using a representation vocabulary. Actually this body of knowledge is a collection of facts about a domain [1].

But not only the researchers of AI tried to give precise definitions for ontology. In the following some more interpretations of ontology will be demonstrated, especially those in which the term is related to specific knowledge bases and which are designed with the purpose of supporting knowledge sharing. According to Guarino's statement ontology is a logical theory, which gives an explicit, partial account of a conceptualization or ontology is a synonym of conceptualization [3. Another way of defining the term is the following: "ontologies are content theories about the sort of objects, properties of objects, and the relations between objects that are possible in a specified domain of knowledge" [1]. Finally, Gruber gives the most general definition for ontologies: "an explicit specification of a conceptualization" [2].

According to AI approach we aimed at developing a representation vocabulary, which serves as the domain ontology of judgment making, rather than creating a body of knowledge, which is a general ontology with which not only this domain can be characterized. The domain ontology of our expert system includes all of those concepts, expressions and the relations between them, which can characterize the given application area (the area of judgment making). This way the communication environment is provided in which the relevant concepts of the application area can be disputed and analyzed.

One of the most important features of the ontological analysis is the ability of clarifying the knowledge structure of a given domain. The clarified terminology enables the ontology to work for coherent and cohesive reasoning purposes. Another relevant feature of ontologies is the ability to support knowledge sharing and reusability. They are content rich forms, the representations of the domain knowledge.

\subsection{Knowledge Base}

The knowledge base contains the logical knowledge of the given application area in the form of statements. All of these statements refer to the concepts of the domain ontology and only these concepts are used. The knowledge base of our prototype system includes rules and regulations determined in the Hungarian Criminal Code, and rules determined during system development.

\subsection{Problem Solving Methods}

The problem solving methods determine that control structure, which can provide the typical, domain independent problem solving strategies [6]. Our prototype system was developed with the AION development tool. This tool joins procedural programming methodology and declarative problem description. In

\footnotetext{
${ }^{1}$ The model is implemented in AION version 9.0
} 
the same program we can create graphical user interface, use database connections and set up a rule base, which is executed by the embedded inference engine of AION [5] (Fig. 1).

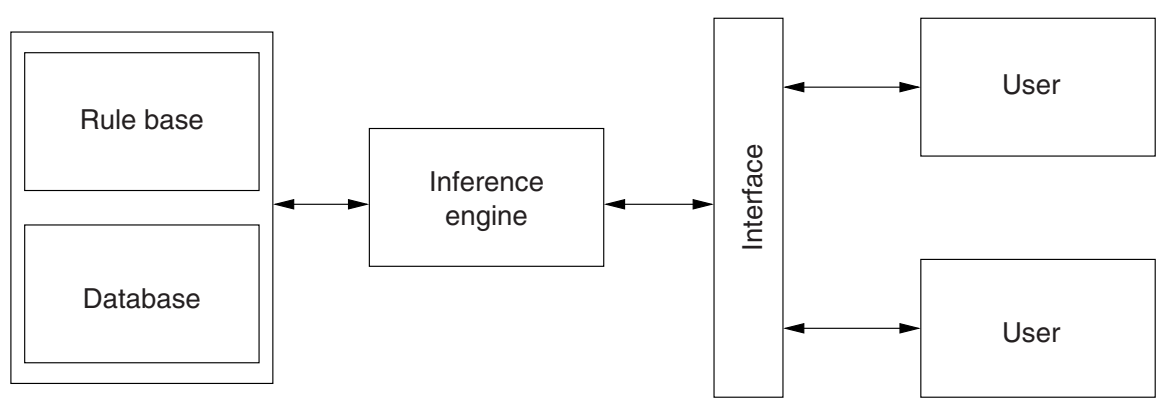

Fig. 1. Major parts of a rule-based expert system

\subsection{Mapping}

During mapping the concepts of the domain ontology and the knowledge base, which consists of statements, the structure of which is determined by the ontology, are matched by the input and output needs of the problem solving methods.

\subsection{Ontology of "Judgment Making"}

In Table 1 following we list those terms, which define the meta-ontology of the domain of judgment making. With defining relations between the main concepts we also determine the structure of knowledge of this specific area. This structuring also defines the progress of work (as Fig. 2 shows) and results correct inferences in our pilot expert system.

In Fig. 3] we demonstrate the concepts and the knowledge structure of a special case. It shows how a verdict can be returned in the case of stealing (together with all the specialties of the case).

\subsection{Using the Pilot System}

When the judge sits down in front of our pilot system, his/her first task is the selection of a case. Normally, the case data comes from the workflow system, and the phase of judgment making follows a number of document creation steps from the prosecution to the preparation of a trial. The judge selects a case and the system loads all the relevant data from the database and shows them on the screen.

The main window of the pilot system consists of two main parts. The primary place to show information is a large frame in the window, in which there is a 
Table 1. Major concepts of the judgment making process

Defendant

The person who committed crime and the Public Prosecutor's Office lays him to charge.

$\overline{\text { Component parts of The statement, in which the Public Prose- }}$ the prosecution cutor's Office determines the type of criminal act, with which it lays the defendant to charge. When the defendant commits more than one criminal act, then the proceeding contains more than one component parts.

General part of the That part of the Hungarian Criminal Code Hungarian Criminal that contains statements, concepts and Code $\quad$ several rules, which apply to all types of criminal acts.

Special part of the That part of the Hungarian Criminal Code Hungarian Criminal that describes penalties regarding each Code criminal act.

Record of the defen- Contains all the criminal acts he/she comdant mitted previously, from which only the last case has relevance in connection with the criminal procedure.

\begin{tabular}{l|l}
\hline Recidivist & $\begin{array}{l}\text { If the criminal act committed by the defen- } \\
\text { dant is within three years regarding the ex- } \\
\text { piration date of his/her last penalty, then } \\
\text { the defendant is recidivist. }\end{array}$ \\
\hline $\begin{array}{l}\text { Frames of possible } \\
\text { judgments }\end{array}$ & $\begin{array}{l}\text { According to the component parts of the } \\
\text { prosecution, the record of the defendant } \\
\text { and rules defined in the Hungarian Crimi- } \\
\text { nal Code the possible penalties of the given } \\
\text { criminal act can be determined, which we } \\
\text { call Frames of possible judgments. }\end{array}$ \\
\hline Judge & $\begin{array}{l}\text { That official person who returns a verdict } \\
\text { in the name of the Hungarian State. }\end{array}$ \\
\hline Judgment & $\begin{array}{l}\text { The law ensures the possibility for the } \\
\text { judge to deliberate the factors of the given } \\
\text { case and to choose that penalty from the } \\
\text { frames of possible judgments, which is } \\
\text { the most appropriate according to his/her } \\
\text { opinion. }\end{array}$
\end{tabular}




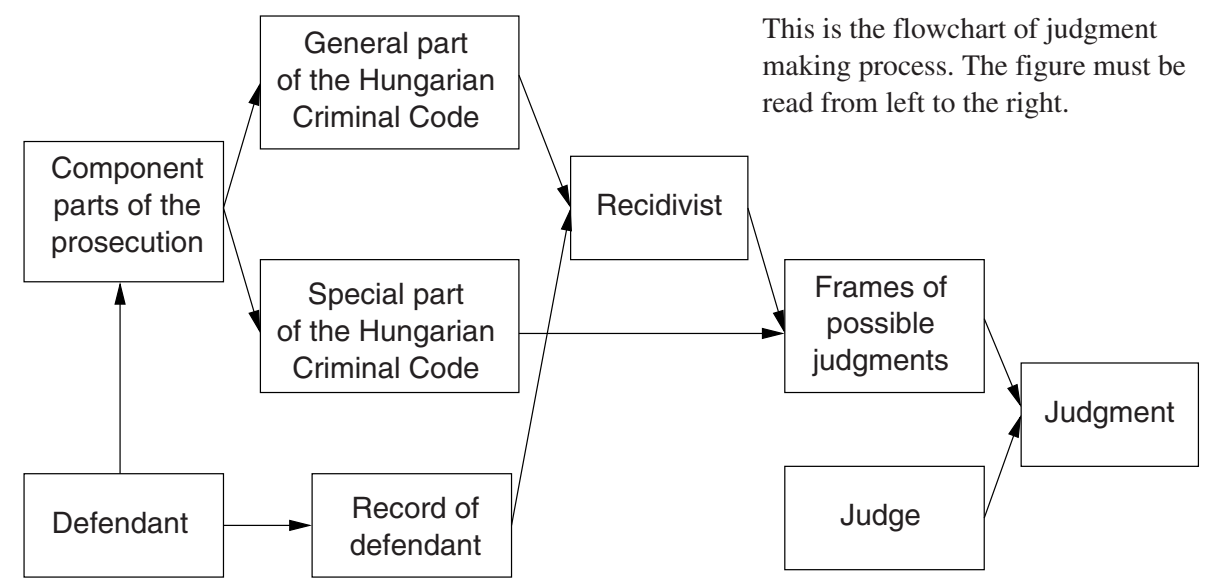

Fig. 2. Relations of main terms of the judgment making domain

tree structure representing the case. The root of this tree contains some identifier and description, such as the number of the case, date and a short description. On the first level of the tree there are the names of defendants, all of which containing more details. Expanding a defendant's subtree, the judge can find the record of the defendant and the component parts of the prosecution. There can be more than one component parts of the prosecution. The pilot system may contain more than one defendant, too. The subtree called component parts of the prosecution contains items, which are named according to the rules of law and the practice of judges, the so-called BK12 descriptions. They are generated with the help of a number of rigid rules and they express the concrete criminal act in one long sentence, containing all the details. This naming convention is common in the practice of judges, it is tightly embedded in their way of thinking, so it is necessary to build up this phrase and show it among the case data, in spite of being a bit confusing for someone not in this profession.

The judge has the right ensured by the law to freely deliberate the information, facts and conditions of the case. This way the system has to handle these decisions and alterations in the case dossier. During trials the judge can alter some details of the case according to his/her decisions. For these amendments there is a special category in the subtree of the defendant: the so-called accepted parts of the prosecution. Compared to the 'normal' parts of the prosecution subtree it shows the differences between the prosecution and the result of trials including the opinions of the judge. This accepted category is the base of rest of the judgment making process.

The judge starts the decision-making by clicking a button and assures the acceptation of case data in a confirmation dialog. This process starts with the execution of those rules, which represent the Hungarian Criminal Code. As we

${ }^{2}$ BK1 description: standard description of a criminal act, including the categorization and the qualification of the act. 

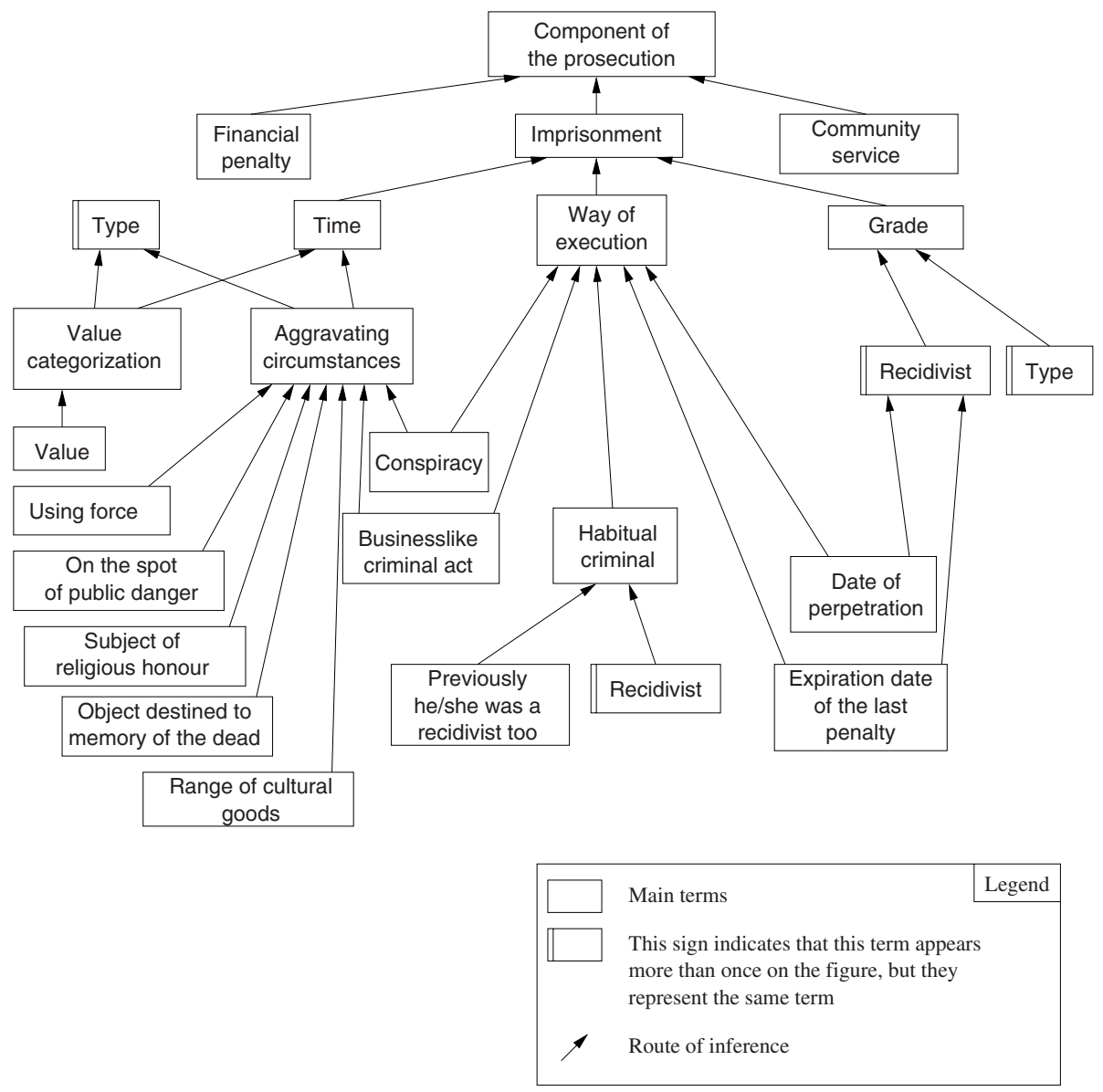

Fig. 3. Relations of the main terms in the case of stealing

mentioned before, the Hungarian legal system is rule-based, which means that only those criminal acts can be punished, which are named by the Hungarian Criminal Code. Moreover the Criminal Code always defines the type of punishment with its possible minimum and maximum degree. The judge has to make the final decision within this interval deliberating other circumstances of the case. The system controls this decision and ensures that it remains among the frames of law. In our prototype system all decisions affecting the judgment are controlled and the result of the process is an automatically generated judgment, which contains only a few parts, which have to be formulated by the judge. This way the majority of formal errors are taken out. This sentence is not "cameraready", it contains only the necessary parts and formulas described in the law. This is where our system is connected again to the above mentioned workflow system in a way that it puts back the judgment into the process of the workflow 
system. This can be done by a common communication platform, for which we have chosen XML. The system puts all data issued in the expert system into an XML form. This way any other system, which implements the XML schema of our pilot system, can use the results of the judgment making process. Since our system covers only the judgment making process from the set of administrative processes of the whole juridical workflow, it shows the result of its process on the screen in two forms: as a human readable text, which follows the formal requirements of the Hungarian judgments, and as a XML form.

\section{Results and Solutions}

In our research project we have tried to find solutions for the previously fully analyzed problems. As we mentioned, there are difficulties in this area, which can be solved by IT tools. In the following we will discuss in details those problems, for which we have found solutions. The efficiency of juridical work can be greatly improved by a workflow system. When the whole proceeding is supported by a workflow system, the lags of the paper-based system will disappear. The document-flow does not require any time and the whole document base is searchable. We have to emphasize again that development of this workflow system was not the task of our R\&D project, but we have simulated a similar environment until the real workflow system will be ready. This is important from the viewpoint of our expert system, because the user's working process begins with the selection of the current case. When the data of the case is recorded into database, they become ready for judgment making. The judge only has to find the appropriate electronic dossier and the expert system is ready to make the verdict. In the pilot system the registration of the relevant case data passes off inside the expert system, and these data can be saved and loaded later. The judgment making work begins with loading the appropriate case data from the case dossier. The Hungarian law ensures deliberation right for judges, so as we mentioned before the law defines only the frames of the possible punishment and it is the judge's task to make an appropriate decision considering facts of the case. The main task of our pilot expert system is to guide the judge through this process and to ensure that the sentence remains within the frames defined by the law.

This kind of workflow system makes possible that judges or clerks work parallel on the same case. The importance of this advantage is not so high for the expert system, but it can increase speed of the whole proceeding, so the arrangement of a case can be done in an even shorter period of time. In our point of view it is even more important that the work and control of judges can be faster. The expert system makes the processing of case data easier, the judge can see through them easily, and ensures the control of the judgment, because it assures that the judge's decision remains within the frames of possible judgments. Some parts of the judgment - which result from the decision of judge and from the case data - are automatically generated, there is only a few part, which the judge have to fill in, in which the justifications will be given concerning the 
decision of the judge. The simplicity of this process can make the work of judges easier and since it is much faster, it can reduce the overwork, too.

Using the expert system can reduce the nowadays so frequent formal errors. This can be done by a simple concept: record data only once in the system. When the Public Prosecutor's Office enters for example the name of the defendant at the beginning of a case, it remains the same through the whole proceeding, there is no need to enter it again. So it will remain correct on all of the descendant papers. Our system ensures that the generated parts of the judgment are also correct. This way the majority of errors are eliminated.

The above described tools make the work of the judges more reliable. With the controlled judgment making and the automatically generated parts of judgment the quality of the judgments can be greatly improved. They cannot be appealed so easily, this way the high workload of the second instance courthouses can be moderated. Guiding and controlling the judgment making process improves the precision of the judgments too, because this process does not allow any failures and deviation from the rules of law. Using the expert system the consistency of judgments is also assured, because the system uses a rule base derived from the law, this way similar cases result similar judgments. Of course, the system only ensures the consistency form the viewpoint of law, because the judge can use his/her free deliberation right. This way it is possible to make very different judgments in similar cases, but it is assured that both are conformed to the law.

The expert system uses the 'electronic dossier' of the workflow system. The input data of judgment making is taken from it and all work made in the system is recorded into that and the result of judge's work is also put into that system. This integration increases the availability of information and assures the consistency of a case dossier. There is a common place of information, which is also searchable and this way reusable. Gathering of information is also easier with an 'electronic dossier', because if a judge wants to deal with a case, gathering of information is reduced to only the selection of a dossier and all the necessary information is available. Our expert system takes part in the whole proceeding from the selection of a case to the automated judgment generation.

\section{Conclusions}

However, there are some areas, which require more attention and analysis and therefore they show the directions of further development. The graphical user interface is a little bit modest because of the limitations of AION. A more userfriendly interface would be able to help the acceptance and the easier spread of the system in the future. The system could be complete if it would connect to a well-implemented and practically used workflow system. Since our system is only a pilot system yet, it contains only a small portion of the Special part of the Hungarian Criminal Code, so it would be complete only if whole Criminal Code would be processed. Moreover it would be useful to expand the operation of the system to other territories of law, for example to the area of civil law. 
Even more experiences could be gained if the system would be compared to other legal expert systems in a similar working environment. The LEFIS Leonardo project 3 will give ample opportunities to do this. The positive consequences could be well used in further development of our system.

The research shows a wider spectrum of possible improvements when the legislation process is analyzed. With an ontology worked out for the legislation process and with better management of it can greatly advance the quality of Hungarian laws. During this process it should be taken into consideration how laws will be appropriate for supporting the use of expert systems.

\section{References}

1. Chandrasekaran B, Josephson J R, Benjamins R. (1999): What Are Ontologies, and Why Do We Need Them? IEEE Intelligent Systems; 14(1): 20-26.

2. Gruber, T. R. (1993): "A Translation Approach to Portable Ontology Specifications", In: Knowledge Acquisition, No. 5. pp. 199-220

3. Guarino, N. and Giaretta, P. (1995): Ontologies and Knowledge bases: towards a terminological clarification. N.J. Mars (ed.) Towards Very Large Knowledge Bases. Knowledge Building and Knowledge Sharing. pp. 25-32, IOS Press.

4. Kö, A. and Gábor, A. (2001): Special Features of Knowledge Management in Public Administration. An Example: the E-Court. 2nd International Workshop of Knowledge Management in e-Government, KMGov-2001 Sienna, Italy

5. Computer Associates Technical Support (1998): Guidelines for Allocating Production Rules Revision, http://support.ca.com/techbases/aion/white_papers/prodrule.html

6. Klein, M. R. and Methlie, L. B. (1995): Knowledge-based Decision Support Systems With Applications in Business, John Wiley \& Sons

7. Molnár, B. (1999): Ismeretszerzés in: Futó (ed.): Mesterséges Intelligencia, AULA Kiadó Kft, Hungary

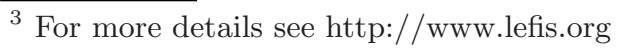

